Передерий Вероника Анатольевна

кандидат социологических наук, доцент кафедры социологии и культурологии Кубанского государственного аграрного университета имени И.Т. Трубилина

\section{НОВЫЕ ПОДХОДЫ К ОЦЕНКЕ КАЧЕСТВ И КОМПЕТЕНЦИЙ ЗАВЕДУЮЩЕГО КАФЕДРОЙ СОВРЕМЕННОГО ВУЗА (РЕЗУЛЬТАТЫ ЭМПИРИЧЕСКОГО ИССЛЕДОВАНИЯ)}

\begin{abstract}
Аннотация:
В статье рассмотрены современные подходы к принципам управления в системе высшего российского образования. Автором изучены вопросы эффективности контроля и управления профессорско-преподавательским составом вуза, разработана модель качеств заведующего кафедрой вуза, отвечающего современным требованиям и параметрам компетентности персонала высшей школы. Материалы статьи позволяют оценить компетентность руководителей кафедр, произвести анализ личностных и профессиональных качеств заведующего кафедрой, ориентированных на достижение эффективности и результативности стратегии вуза по предоставлению образовательных услуг населению. В работе изложены основные результаты эмпирического исследования, проведенного среди студентов и профессорскопреподавательского состава кубанского вуза, нацеленного на улучшение методов управления, обеспечивающих высокую конкурентоспособность вуза на рынке образовательных услуе. По мнению участников опроса, модель качеств заведующего кафедрой вуза представлена тремя группами качеств: личностными, коммуникативно-организаторскими и профессиональными.
\end{abstract}

Ключевые слова:

модель качеств заведующего кафедрой, профессиональная компетентность, заведующий кафедрой вуза, коммуникативно-организаторские качества, личностные качества, профессиональные качества, морально-нравственные качества, управленческая деятельность.
Perederiy Veronika Anatolyevna

PhD in Social Science, Associate Professor, Sociology and Cultural Studies Department, Kuban State Agrarian University

\section{NEW APPROACHES TO ASSESS QUALITIES AND SKILLS OF \\ THE HEAD OF THE DEPARTMENT AT THE CONTEMPORARY UNIVERSITY (THE EMPIRICAL RESEARCH RESULTS)}

Summary:

The paper discusses modern approaches to management principles in Russian higher education. The author examines the effective control and management of the faculty of the university, develops the quality model for the head of the department who meets the contemporary requirements of higher education staff and has the necessary skills. The research allows one to assess the competence of the head of the department, analyze his personal and professional skills aimed at achieving efficiency and effectiveness of the university strategy to provide educational services to the public. The paper presents the main results of the empirical research conducted among students and academic staff of Kuban university intended to improve management practices making a university more competitive on the educational market. In the opinion of the survey respondents, the quality model for the head of the university's department includes three groups of qualities: personal, communicative and managerial, professional ones.
Keywords:

quality model for the head of the department, professional skills, head of the university's department, communicative and managerial qualities, personal qualities, professional qualities, moral qualities, managerial activity.

Современной наукой накоплен значительный опыт зарубежных и отечественных исследований в области изучения личностных и профессиональных качеств, управленческих особенностей руководителей высшего и среднего звена. Ученые-исследователи социогуманитарной направленности (социологи, психологи, экономисты, политологи) достаточно внимания уделяют вопросам профессиональной компетентности, личностных коммуникативных и организаторских способностей, морально-этического и психологического облика руководителя. Статусно-ролевые функции руководителя, проблемы социального управления рассмотрены в работах таких социологов-классиков, как Т. Адорно, М. Вебер, Г. Зиммель, Т. Парсонс, Г. Тард, что впоследствии отразилось в работах отечественных ученых 3. Голенковой, В. Мансурова, Г. Осипова, В. Пузикова, Ж. Тощенко, М. Шведовой и др. Научные исследования последних лет посвящены проблемам изучения лидерства, влиянию стиля руководства на поведение подчиненных, эффективности деятельности организации (П. Глухов, В. Кузьмин, А. Замулин). Анализом процесса управления и качества образовательных услуг в системе высшего образования занимались В. Владимиров, В. Герчикова, Л. Дьячкова. Вопросы соотнесения категорий в парах «индивидуализм - коллективизм», «форма лидерства (харизматическое лидерство) - вовлеченность сотрудников в 
производственный процесс» раскрывают в своих работах современные зарубежные исследователи Т.А. Джексон, Дж.Р. Мейер и Сяо-Хуа (Фрэнк) Ван [1, р. 95]. О позитивном влиянии трансформационного лидерства на работников пишут и российские ученые Е.С. Балабанова и В.Э. Деминская, которые определяют управление как двунаправленный процесс, но анализ образа руководителя в сознании подчиненных, по их мнению, является наиболее значимым [2, с. 270].

Тем не менее недостаточно разработана область социологии труда по изучению и оценке значимых качеств руководящего состава современного российского вуза, находящаяся на стыке с психологией управления. Мотивация, ценностные ориентации, определение приоритетов в управлении профессорско-преподавательским составом кафедры со стороны заведующего как одного из ключевых управленческих механизмов системы российского высшего образования послужили отправными факторами для проявления научного интереса к исследованию данной проблематики в рамках ФГБОУ ВО «Кубанский государственный аграрный университет имени И.Т. Трубилина» (далее - КубГАУ). Мы согласны с мнением А.В. Родионова о том, что управление качеством образования в вузе сегодня нуждается в структуризации и анализе ключевых процессов, связанных с удовлетворением требований потребителей, что в свою очередь предполагает формирование процессно-ориентированного управления кадровым и образовательным потенциалом вуза [3, с. 96]. В системе управления вуза необходимо создавать партнерские взаимодействия, ориентированные на всех субъектов образовательного процесса [4, с. 89].

Считаем, что, ориентируясь на международные стандарты менеджмента качества в области образовательного процесса, управлять членами профессорско-преподавательского состава (ППС) кафедры должен компетентный руководитель с соответствующими системой знаний, образованием, подготовкой, навыками и опытом. В связи с этим в 2016-2017 гг. лаборатория социальных проблем при кафедре социологии и культурологии КубГАУ организовала и провела социологическое исследование «Модель качеств заведующего кафедрой современного вуза». Объектом исследования выступили руководители кафедр, предметом - качества и коммуникативно-организаторские способности заведующих кафедрами КубГАУ. Цель исследования - разработка модели качеств заведующего кафедрой вуза, отвечающего современным требованиям и параметрам компетентности персонала высшей школы, высокому качеству предоставляемых образовательных услуг при подготовке высококвалифицированных специалистов. Для реализации цели решались следующие задачи: определить текущую компетентность заведующих кафедрами, оценить качество выполнения профессиональной деятельности руководителями ППС кафедр вуза, выявить систему личностных и профессиональных качеств заведующего кафедрой.

Исследование имело трехплоскостной формат и проходило в три этапа с разработкой соответствующего инструментария. Первый этап - оценку качеств заведующего - производила студенческая аудитория, на втором этапе уровень выполнения профессиональной деятельности оценивал профессорско-преподавательский состав вуза, на заключительном этапе - сами руководители 83 кафедр аграрного вуза.

В социологическом опросе (анкетировании) приняли участие 332 преподавателя КубГАУ. Социально-демографические показатели респондентов дифференцированы по возрасту: до 30 лет (7,6 \%), от 30 до 50 лет $(47,7)$ и свыше 50 лет $(44,7 \%)$ и научно-педагогическому стажу: менее 5 лет $(8,3 \%)$, от 5 до 10 лет (13,6), от 10 до 20 лет $(31,0)$ и более 20 лет (47,1\%). Среди них 18,2 \% доктора наук, работающие в должности профессора, 5,3 \% - доктора наук, работающие доцентами, 6,8 \% - кандидаты наук с должностью профессора, 57,6 \% - кандидаты наук / доценты, 12,1 \% опрошенных не имеют научной степени. 25 респондентов состава ППС аграрного вуза имеют звания, которые они заслужили, работая в системе высшего образования, среди них: ветеран труда, лауреат премии Правительства РФ, заслуженный работник культуры Кубани, заслуженный работник сельского хозяйства Кубани, лауреат премии администрации Краснодарского края, почетный работник агропромышленного комплекса России, изобретатель СССР, лауреат государственной премии в области науки и техники.

Выборка респондентов студенческой аудитории составила 300 человек с дифференциацией по гендерному признаку: юноши - 122 чел., девушки - 178 чел.; курсу обучения: 3-й курс 180 чел., 4-й курс - 120 чел.; направленности обучения (факультеты): фринансы и кредит - 80 чел., архитектурно-строительный - 40, учетно-финансовый - 40, агрономии и экологии - 60, механизации - 40, ветеринарной медицины - 40 чел.

Согласно данным опроса, 65,2 \% профессорско-преподавательского состава КубГАУ отметили, что заведующий кафедрой, на которой они работают, является неформальным лидером коллектива. Ответы на вопрос: «Продолжите утверждение: “Профессиональная компетентность для Вашего заведующего..."» - распределились следующим образом: «наиболее важна» (72,0 \%), «менее важна, скорее важны организаторские качества» $(17,4$ \%), «менее важна, приоритет отдаю деловым качествам» (6,1%), «менее важна, доминируют морально-нравственные 
качества» (4,5 \%). 100 \% респондентов согласны с мнением, что заведующий кафедрой обязан обладать высокими нравственными качествами. Среди них лидируют: честность (18,6 \%), справедливость $(10,3)$, целеустремленность $(9,5)$, порядочность $(8,7)$, вежливость $(8,1)$, тактичность $(7,7)$, настойчивость $(7,6)$ и толерантность $(6,0 \%)$.

На вопрос: «Какими личностными качествами обладает заведующий кафедрой, который(ая) вел(а) или ведет у Вас определенные предметы?» - студенческая аудитория выделила: самоорганизованность $(30,3$ \%), коммуникабельность $(15,4)$, доброжелательность $(12,2)$, высокую эрудицию $(12,2)$, толерантность $(10,6)$, красноречие $(9,8)$, чувство юмора $(3,6)$, гибкость и нестандартное мышление $(2,4)$, строгость и справедливость $(2,4)$, эмоциональность $(1,1 \%)$. Опрошенные студенты $(39,4$ \%) среди прочих компетенций, которыми, по их мнению, должен обладать заведующий кафедрой современного вуза, выделяют творческий (креативный) подход к управлению персоналом и к ведению учебного процесса, что совпадает с мнением А.Н. Камировой, которая полагает, что креативная деятельность необходима современной системе образования. Ученый отмечает важность не только креативной составляющей среди компетенций управленческого персонала, но и креативной среды вуза, диффееренцируя понятия индивидуальной и коллективной креативности [5, с. 167].

На рисунке 1 представлен набор коммуникативно-организаторских качеств, которыми должен обладать заведующий кафедрой современного вуза (по мнению участников опроса).

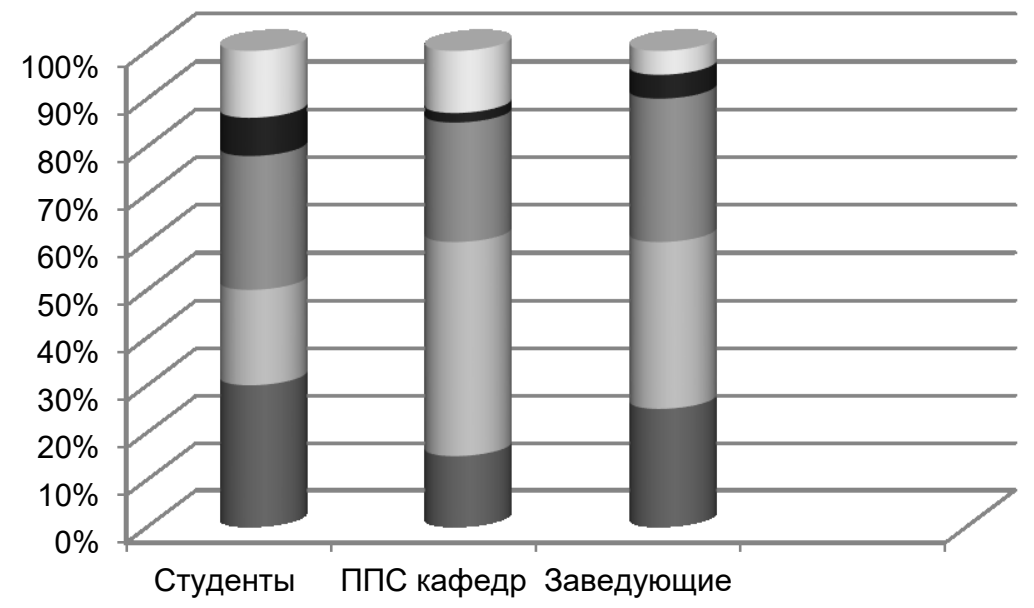

Умение выслушать

- Распределение полномочий среди ППС

- Отношения с ректоратом

— Отношения с подчиненными

Ш Отношения со студентами

\section{Рисунок 1 - Необходимый набор коммуникативно-организаторских качеств руководителя кафедры вуза (по мнению участников опроса), \%}

Как видно из рисунка 1, умение строить отношения с персоналом кафедры, студентами и ректоратом выделены абсолютно всеми субъектами опросной методики, далее следуют умение выслушать и распределение полномочий среди сотрудников.

В системе компетенций заведующего кафедрой современного вуза определены профессиональные $(38,6 \%)$, управленческие $(33,3)$, научные $(14,2)$, психолого-педагогические $(10,0)$, экономические $(3,0)$ и правовые $(0,9 \%)$ компетенции. 68,9 \% ППС КубГАУ отметили способность заведующего кафедрой к продолжительной и напряженной работе. Большинство членов ППС вуза считают, что их руководитель мгновенно (55,2%) принимает правильные решения и в кратчайшие сроки может изменить тактику (концепцию кафедры), если этого потребует вышестоящее руководство $(56,6 \%)$.

76,5 \% ППС вуза оценили уровень выполнения профессиональной деятельности своим руководителем как «высокий», 23,5 \% - «средний». На вопрос: «Влияет ли профессиональный уровень Вашего заведующего кафедрой на деятельность профессорско-преподавательского состава кафедры?» - утвердительно ответили 78,8 \% респондентов, отрицательно - 2,3 \%, затруднились с ответом - 18,9 \%. Менее половины опрошенных преподавателей КубГАУ $(47,0$ \%) считают, что в вузе необходим кадровый резерв на должность заведующего кафедрой. Были даны рекомендации по профессиональной подготовке руководителей кафедры, среди них: фрормирование профессиональных знаний, умений в сфере управления (46,1\%), опыт работы на конкретной должности заведующего $(42,4)$. Среди прочих $(11,5 \%)$ отмечены согласованность в решениях кафедры, отстаивание интересов сотрудников. Таким образом, модель качеств заведующего кафедрой вуза, по мнению участников опроса, представлена тремя группами интегральных составляющих: личностные, коммуникативно-организаторские и профессиональные качества. 
Резюмируя данные проведенного эмпирического исследования, можем заключить, что заведующий кафедрой вуза при непосредственном контроле за деятельностью своих подчиненных активно участвует в образовательно-воспитательном процессе, научно-теоретических и прикладных исследованиях по профилю кафедры. Одновременно с этим многие заведующие являются членами редакционных советов и коллегий ведущих российских научных журналов, осуществляют научное руководство кандидатских и докторских диссертаций, пользуются уважением и авторитетом среди профессорско-преподавательского состава вуза, тем самым положительно влияют на уровень и качество профессиональной деятельности персонала, способствуя позитивным преобразованиям в системе многоуровневой подготовки специалистов. Качество подготовки специалистов для всех сорер жизнедеятельности современного общества в значительной степени зависит от высококомпетентного кадрового состава вуза, управление которым является весьма непростой задачей, требующей от руководства системного анализа и оценки эффеективности работы персонала, своевременного принятия результативных решений.

\section{Ссылки:}

1. Jackson T.A., Meyer J.P., Xiao-Hua (Frank) Wang. Leadership, Commitment, and Culture: A Meta-Analysis // Journal of Leadership \& Organizational Studies. 2013. Vol. 20, no. 1. P. 84-106. https://doi.org/10.1177/1548051812466919.

2. Балабанова Е.С., Деминская В.Э. Руководитель как трансформационный лидер: роль личностных качеств и управленческих практик // Российский журнал менеджмента. 2017. Т. 15, №3. С. $263-288$. https://doi.org/10.21638/11701/spbu18.2017.301.

3. Родионов А.В. Усовершенствование системы управления кадровым и образовательным потенциалом региона на основе процессного подхода // Карельский научный журнал. 2014. № 3 (8). С. 95-97.

4. Люханова С.В. Система менеджмента вуза как сложная многоуровневая система управляющих элементов // Менеджмент в России и за рубежом. 2017. № 2. С. 89-96.

5. Камирова А.Н. Стратегическое планирование: ориентация вуза на устойчивое развитие и конкурентные преимущества // Управленческое консультирование. 2017. № 1 (97). С. 166-172.

\section{References:}

Balabanova, ES \& Deminskaya, VE 2017, 'Supervisors' Transformational Leadership: Personality and Management Practices as Antecedents', Russian Management Journal, vol. 15, no. 3, pp. 263-288. https://doi.org/10.21638/11701/spbu18.2017.301.

Jackson, TA, Meyer, JP \& Xiao-Hua (Frank) Wang 2013, 'Leadership, Commitment, and Culture: A Meta-Analysis', Journal of Leadership \& Organizational Studies, vol. 20, no. 1, pp. 84-106. https://doi.org/10.1177/1548051812466919.

Kamirova, AN 2017, 'Strategic planning: focus of higher education institution on the sustainable development and competitive advantages', Upravlencheskoye konsul'tirovaniye, no. 1 (97), pp. 166-172, (in Russian).

Lyukhanova, SV 2017, 'University management system as a complex multilevel control system', Menedzhment v Rossii i za rubezhom, no. 2, pp. 89-96, (in Russian).

Rodionov, AV 2014, 'The improvement of the management of personnel and educational potential of the region on the basis of the process approach', Karel'skiy nauchnyy zhurnal, no. 3 (8), pp. 95-97, (in Russian). 